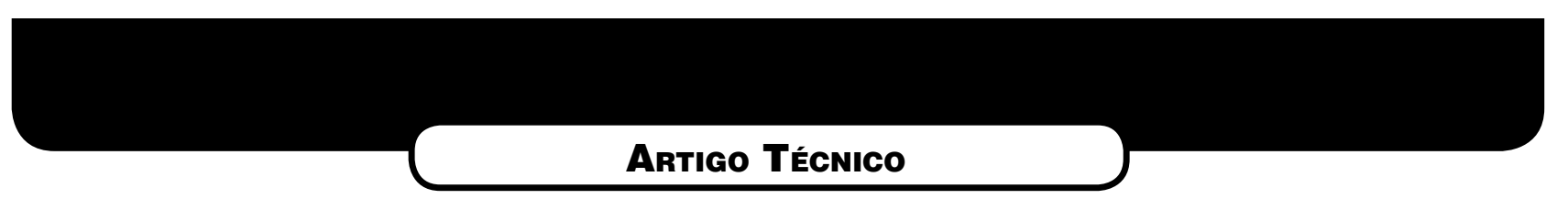

\title{
Tratamento anaeróbio de Pentaclorofenol em ReAtor DE LEITO FLUIDIFICADO ALIMENTADO COM ÁGUA RESIDUÁRIA SINTÉTICA CONTENDO GLICOSE COMO FONTE ÚNICA DE CARBONO
}

\author{
ANAEROBIC TREATMENT OF PENTACHLOROPHENOL IN A FLUIDIZED BED \\ REACTOR FED WITH SYNTHETIC WASTEWATER CONTAINING GLUCOSE AS A \\ SINGLE CARBON SOURCE
}

\begin{abstract}
FLAVIO BENTES FREIRE
Engenheiro Civil pela EESC/USP. Mestre em Hidráulica e Saneamento pela EESC/USP. Doutor em Hidráulica e Saneamento pela EESC/USP. Professor adjunto do Centro de Tecnologia, Universidade Estadual de Maringá

\section{EDUARdo CLETo Pires}

Engenheiro Mecânico pela EESC/USP. Mestre em Engenharia Mecânica pela PUC/RJ. Doutor e Livre Docente em Hidráulica e Saneamento pela EESC/USP. Professor Titular do Departamento de Hidráulica e Saneamento da EESC/USP

\section{JoSÉ TEIXEIRA FREIRE}

Bacharel em Física pela Universidade Federal do Rio de Janeiro. Mestre em Hidráulica e Saneamento pela EESC/USP. Doutor em Engenharia Química pela COPPE/UFRJ. Professor Titular do Departamento de Engenharia Química/UFSCar

$$
\text { Recebido: 11/12/07 Aceito: 27/08/08 }
$$
\end{abstract}

\section{RESUMO}

Neste trabalho foi utilizado um reator anaeróbio de leito fluidificado (RALF), tratando água residuária sintética contendo pentaclorofenol (PCP), submetido a condições operacionais menos idealizadas. Utilizou-se um reator com volume de 16 litros, com partículas de carvão ativado granular como meio suporte. O desempenho do reator foi verificado pelas análises usuais de monitoramento $(\mathrm{pH}$, alcalinidade, DQO, ácidos voláteis) e também por análises de microscopia e concentração de PCP. A presença de PCP no sistema, nas concentraçôes utilizadas, não alterou de maneira significativa a qualidade da biomassa presente, e nem os parâmetros de monitoramento. Em concentrações afluentes de PCP variando de 1 a $6 \mathrm{mg} / \mathrm{L}$, foram observadas eficiências médias de remoção de $92 \%$ e $70 \%$, respectivamente.

PALAVRAS-CHAVE: Pentaclorofenol, reator anaeróbio de leito fluidificado, carvão ativado granular, água residuária sintética, fonte única de carbono, biomassa não adaptada.

\begin{abstract}
In the present work, an anaerobic fluidized bed reactor (AFBR) was used for the treatment of a synthetic wastewater containing pentachlorophenol (PCP) subjected to less idealized operating conditions. The reactor was a 16 litres tank with granular activated carbon particles as support media. Evaluation of AFBR performance was done by the analysis of usual monitoring parameters ( $p H$, alkalinity, COD, volatile acids) together with microscopy and PCP concentration analysis. The presence of PCP under the concentrations used did not significantly alter the amount of biomass and the performance monitoring parameters. Removal average efficiencies of the order of $92 \%$ and $70 \%$ were obtained for PCP inflow concentrations in the range of 1 to $6 m g / l$.
\end{abstract}

KEYWORDS: Pentachlorophenol, anaerobic fluidized bed reactor, granular activated carbon, synthetic wastewater, single source of carbon; non-previously adapted biomass.

\section{INTRODUÇÃO}

Os compostos organoclorados, tais como os clorofenóis, são objeto de grande preocupação e de estudos sistemáticos, principalmente pela sua elevada toxicidade e pelo seu alto poder de persistência no meio ambiente. Os clorofenóis são utilizados em amplo espectro de ativida- des, como na preservação de madeira, em herbicidas, fungicidas, biocidas em geral, e aparecem também como subprodutos do branqueamento do papel, em processos que utilizam cloro, na incineração de resíduos municipais, na cloração de águas residuárias, dentre outras (Parker et al, 1993; Flora et al, 1994; Basu et al, 1996; Blakley et al, 1998).
Essas características fazem com que em muitos países esses compostos sejam submetidos a legislações cada vez mais restritivas. Contudo, conseqüências de sua utilização desenfreada até um passado não tão distante e relatos atuais de situações críticas mostram que o problema persiste e está longe de uma solução. No Brasil, um dos casos mais famosos de conta- 
minação por pentaclorofenol (PCP) envolve a Rhodia S.A., de Cubatão (Saia, 2005). Além de políticas públicas eficientes, e da fiscalização e punição dos responsáveis, existe a necessidade do desenvolvimento de tecnologias tanto para a recuperação de áreas contaminadas como para o tratamento dos efluentes na fonte de geração.

A comunidade científica tem papel importantíssimo nesse contexto, estudando, desenvolvendo e viabilizando alternativas para minimizar os impactos ao meio ambiente. A degradação lenta dos compostos orgânicos halogenados sob determinadas condiçôes ambientais, bem como os elevados custos e resultados discutíveis de algumas tecnologias de tratamento, tem aumentado $\mathrm{o}$ interesse por processos biológicos de degradação. Segundo Field et al (1995), a dificuldade de degradação por processos aeróbios de compostos altamente clorados, e a constatação da existência e degradação destes compostos em ambientes anaeróbios naturais, torna os processos anaeróbios uma ótima alternativa

Os processos biológicos anaeróbios envolvendo reatores com biomassa imobilizada proporcionaram um grande avanço no tratamento das mais diversas substâncias poluentes, principalmente por possibilitarem a retenção de biomassa dentro do sistema, aumentando a relação entre o tempo de retenção celular e o tempo de detenção hidráulica (TDH). Dessa forma, além de minimizar a perda de biomassa no efluente, essa técnica permitiu que fossem aplicados $\mathrm{TDH}$ reduzidos, e conseqüentemente, que reatores com volumes menores fossem projetados.

O reator anaeróbio de leito fluidificado (RALF) ainda acrescenta outras vantagens, tais como: ótimo contato entre as fases líquida e sólida; controle da espessura do biofilme; são evitados problemas de escoamentos preferenciais, de entupimento, e de retenção de gás, geralmente encontrados em reatores de leito fixo; o biofilme fino permite boa difusão do substrato para as camadas mais profundas (Metcalf \& Eddy, 1991; Speece, 1996; Campos \& Pereira, 1999).

Uma alternativa muito utilizada para viabilizar os estudos relacionados com o tratamento anaeróbio de clorofenóis é acrescentá-los a águas residuárias sintéticas que ofereçam matéria orgânica como fontes de car- bono e energia aos microrganismos. Nessa adaptação, entretanto, condições extremamente favoráveis que não traduzem efetivamente as situações reais podem ser aplicadas. De fato, é constatado na literatura que remoções quase totais de vários compostos clorofenóis, dentre eles o PCP foram conseguidas mediante elevado número de fontes de carbono, alta concentração de matéria orgânica e elevados tempos de detenção hidráulica, por exemplo (Wang et al, 1986; Gardner et al, 1988; Pfeffer e Suidan, 1989; Tsuno et al, 1996; Suidan et al, 1996; Khodadoust et al, 1997).

Outro problema está relacionado com a otimização das unidades. Buzzini \& Pires (2002) indicam a necessidade de estudos para o desenvolvimento de reatores biológicos mais eficientes, ocupando menor volume e, se possível, aliando a esta característica um baixo consumo de energia.

Em escala industrial, dificilmente uma única unidade de tratamento cumprirá os restritos níveis de descarga exigidos pelas legislações, sendo necessário o desenvolvimento de um sistema de tratamento, geralmente com várias unidades. Dessa maneira, no laboratório, mesmo se uma determinada pesquisa tenha como enfoque um reator, é recomendável que essa unidade sempre seja visualizada como uma parte integrante de um "todo", o que faz uma grande diferença em relação a analisá-la isoladamente. Não é necessário que a remoção de poluentes e matéria orgânica seja quase total, o que é praticamente inatingível, mesmo a custo de elevadíssimos tempos de detenção hidráulica, mas sim compatível com as outras unidades do sistema de tratamento. Atualmente diversas alternativas de tratamento combinado são avaliadas, onde em muitos casos a etapa anaeróbia desempenha um papel de pré-tratamento.

Acreditando que é possível obter bons resultados mesmo em panoramas operacionais mais restritivos, este trabalho leva em consideração o tratamento anaeróbio do PCP sob condiçôes menos favoráveis, tais como fonte única de carbono (glicose), menor concentração de matéria orgânica e menor tempo de detenção hidráulica, diferentemente das condiçōes observadas em boa parte da literatura.

\section{MATERIAL E MÉTODOS}

\section{Reator RALF}

O reator anaeróbio de leito fluidificado, em que os estudos foram realizados, é mostrado na Figura 1.

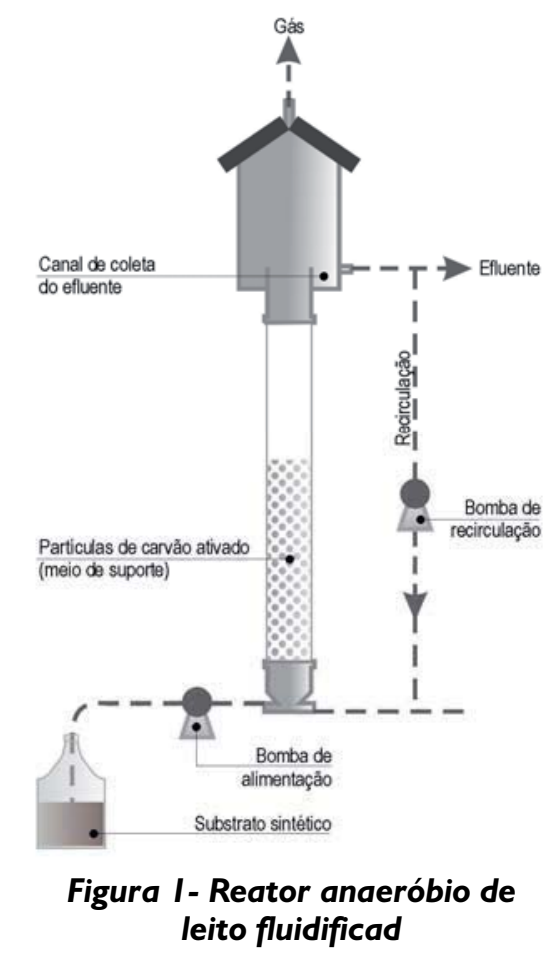


O reator, com volume de 16 litros e $180 \mathrm{~cm}$ de altura e $9,3 \mathrm{~cm}$ de diâmetro, era constituído de entrada, corpo principal e seção de separação, conectadas por flanges e parafusos. A entrada, responsável pela distribuição do afluente, foi feita em aço inoxidável, e tinha uma placa perfurada para uma distribuição homogênea do fluido no reator. $\mathrm{O}$ distribuidor utilizado foi uma chapa de inox com $0,1 \mathrm{~cm}$ de espessura, perfurada com orifícios de $0,15 \mathrm{~cm}$ e com $15 \%$ de área livre.

O corpo do reator era composto por um tubo de vidro de $0,3 \mathrm{~cm}$ de espessura, $120 \mathrm{~cm}$ de altura e $9,3 \mathrm{~cm}$ de diâmetro. Ao longo de sua altura foram colocados amostradores espaçados de $40 \mathrm{~cm}$.

A seção de saída do reator também em aço inoxidável, foi responsável pela saída do efluente, do gás produzido, e pela saída da parcela do efluente a ser recirculada. A separação do gás era obtida através da "queda" do líquido até o canal de coleta do efluente (indicado na figura 1). Esse princípio foi também utilizado em diversos trabalhos que envolviam estudos fluididinâmicos de reatores de leito fluidificado (Briens et al, 1997; Miura \& Kawase, 1998; Safoniuk et al, 1999) e dispensa a utilização de anteparos defletores para a separação de fases.

\section{Material suporte}

O material suporte utilizado como "recheio" do RALF foi o carvão ativado granular para filtros de piscina. Através de peneiramento foram selecionadas partículas com diâmetros médios de 3,08 mm. O carvão ativado foi escolhido por representar um material de baixa densidade $\left(1,21 \mathrm{~g} / \mathrm{cm}^{3}\right)$ e elevada porosidade $(22,5 \%)$. Sua viabilidade como meio suporte em reatores biológicos é difundida na literatura (Speece, 1996; Campos \& Pereira, 1999).

\section{Água residuária sintética}

A água residuária utilizada em todos os experimentos da pesquisa, baseada em Nery et al (2001), foi escolhida em função da simplicidade para a preparação de grandes volumes. $\mathrm{Na}$ sua composição original, ela teve como ponto de partida a solução utilizada para determinação de Demanda Bioquímica de Oxigênio (DBO), proposta pelo Standard Methods for the Examination of Water and Wastewater
(APHA, 1998), e era constituída por nutrientes e três fontes de carbono: glicose, acetato de amônia e metanol. Com pequenas modificações, tais como a introdução de glicose como única fonte de carbono, a água residuária foi desenvolvida e resultou na descrição mostrada na Tabela 1 .

Os valores apresentados na tabela são baseados em uma concentração de glicose de 1000 mg/L, e Demanda Química de Oxigênio (DQO) também da ordem de 1000 mg/L. Para concentraçôes de DQO diferentes da estipulada, bastava acrescentar os reagentes na proporção desejada.

\section{Inoculação do reator}

O inóculo utilizado em todos os experimentos foi proveniente de reator anaeróbio de manta de lodo e escoamento ascendente (UASB), tratando água residuária de abatedouro de aves (Dacar Industrial S.A.), sediada em Tietê, SP. Este lodo foi adotado porque era bem granulado e apresentou grande diversidade morfológica.

No processo de inoculação, inicialmente o reator foi alimentado (em circuito fechado) por uma suspensão à base de efluente sintético (DQO $\approx 500 \mathrm{mg} / \mathrm{L}$ ), e do lodo de inóculo macerado em liquidificador. A suspensão foi elaborada numa proporção tal que resultasse numa concentração de sólidos totais voláteis de aproximadamente $200 \mathrm{mg} / \mathrm{L}$. Esse princípio de imobilização de biomassa mostrou-se eficiente tanto para sistemas em escala pequena como para reatores em maior escala, pois promove simultaneamente a adesão de biomassa nos suportes e a adaptação desses microrganismos ao substrato (Silva et al, 2006). A suspensão (lodo macerado + efluente sintético) foi bombeada para dentro do reator, sob uma baixa vazão de alimentação (cerca de $1 \mathrm{~L} /$ hora). Essa solução era renovada a cada 2 dias.

Após a fase de imobilização de biomassa, com duração de 28 dias, o reator ficou por cerca de 7 dias trabalhando como um filtro biológico, ou seja, como um reator de leito fixo, sendo alimentado apenas com o efluente, sem a introdução de lodo macerado. Essa fase foi programada para servir como uma transição entre as condiçôes de circuito fechado e de leito fluidificado, para uma melhor adaptação da biomassa.

Após esse processo de inoculação, o reator foi então submetido às condiçôes operacionais típicas de um RALF. Durante um período inicial de operação ele foi alimentado apenas com a água residuária sintética, e a partir de então o PCP foi sendo introduzido.

\section{Preparação de solução estoque de PCP}

A solução de PCP foi elaborada em pH elevado, com auxílio de hidróxido de sódio $(\mathrm{NaOH})$. Dessa maneira foi elaborada uma solução estoque de $7 \mathrm{~g} / \mathrm{L}$ de PCP que foi acrescentada ao afluente, de maneira a resultar nas concentrações desejadas para aplicar ao RALF.

Tabela I - Componentes da água residuária sintética

\begin{tabular}{cc}
\hline Composto & Concentração $(\mathrm{mg} / \mathrm{L})$ \\
\hline Glicose & 1000 \\
Uréia & 62,5 \\
Sulfato de níquel & 0,5 \\
Sulfato ferroso & 2,5 \\
Cloreto férrico & 0,25 \\
Cloreto de cobalto & 0,04 \\
Oxido de selênio & 0,035 \\
Fosfato de potássio monobásico & 42,5 \\
Fosfato de potássio dibásico & 10,85 \\
Fosfato de sódio dibásico & 16,7 \\
Bicarbonato de sódio & 1000 \\
\hline
\end{tabular}




\section{Operação e monitoramento do desempenho do reator}

Com o reator submetido a um tempo de detenção hidráulica $(\mathrm{TDH})$ de 8,0 horas e concentrações afluentes de DQO próximas a $1000 \mathrm{mg} / \mathrm{L}$, o PCP foi introduzido no sistema inicialmente na concentração de $1 \mathrm{mg} / \mathrm{L}$. Na seqüência da operação, foram aplicadas concentrações de 2, 4 e $6 \mathrm{mg} / \mathrm{L}$.

Em sua totalidade, após a introdução do PCP o reator funcionou por 95 dias, englobando os 15 primeiros dias em que não foram realizadas análises, para adaptação às novas condiçôes de entrada, e mais 80 dias de funcionamento com monitoramento. Pela inexistência de análises, julgou-se conveniente que o primeiro período fosse excluído da apresentação dos resultados.

A Tabela 2 mostra os parâmetros operacionais do reator no período de operação com o PCP.

A Tabela 3 mostra um quadro resumo com as fases de operação do reator depois da colocação do PCP no sistema, contendo a duração e a concentração de PCP $\left(\mathrm{C}_{\mathrm{PCP}}\right)$ para cada fase. Durante a operaçáo do reator com PCP, todos os parâmetros operacionais apresentados na Tabela 2 foram mantidos.

O monitoramento do desempenho do reator foi realizado através das seguintes análises físico-químicas: $\mathrm{pH}$, DQO, alcalinidade e ácidos voláteis. Todas as análises seguiram os padrões e procedimentos descritos no Standard Methods for the Examination of Water and Wastewater (APHA, 1998), com exceção da análise de ácidos voláteis, que foi realizada por cromatografia gasosa, baseada em Moraes et al (2001). As concentrações de PCP foram analisadas através de cromatografia gasosa (Damianovic et al, 2007). As biopartículas, ou seja, partículas de carvão com biomassa aderida, foram retiradas do reator através do amostrador próximo ao fundo, e a caracterização qualitativa da biomassa foi obtida através de análise de microscopia eletrônica de varredura (MEV), de acordo com Araújo et al (1998). Para efeito de comparação, a microscopia eletrônica de varredura foi realizada em biopartículas retiradas antes da introdução do PCP e também ao final do experimento. A estimativa quantitativa da biomassa aderida ao CAG foi baseada em método descrito por Chen \& Chen (2000).
Tabela 2 - Informações e parâmetros operacionais do RALF

\begin{tabular}{|c|c|c|}
\hline \multicolumn{2}{|c|}{ Informação } & Desrição \\
\hline \multicolumn{2}{|c|}{ Dias de operação } & 95 \\
\hline \multicolumn{2}{|c|}{ Diâmetro médio do CAG (mm) } & 3,08 \\
\hline \multicolumn{2}{|c|}{ DQO prevista no afluente $(\mathrm{mg} / \mathrm{L})$} & 1000 \\
\hline \multicolumn{2}{|c|}{ TDH (horas) } & 8,0 \\
\hline \multicolumn{2}{|c|}{ Vazão afluente (L/d) } & 48 \\
\hline \multicolumn{2}{|c|}{ Carga orgânica (gDQO/d) } & 48 \\
\hline \multicolumn{2}{|c|}{ Taxa de carregamento orgânico (gDQO/L.d) } & 3,0 \\
\hline \multicolumn{2}{|c|}{ Altura estática do leito - repouso $(\mathrm{cm})$} & 60 \\
\hline \multicolumn{2}{|c|}{ Expansão do leito (\%) } & 35 \\
\hline \multicolumn{3}{|c|}{$\begin{array}{c}\text { Tabela } 3 \text { - Fases operacionais e suas respectivas } \\
\text { concentrações de PCP aplicadas ao RALF }\end{array}$} \\
\hline Fase & Dias & $\begin{array}{c}\mathrm{C}_{\mathrm{PCP}} \\
(\mathrm{mg} / \mathrm{L})\end{array}$ \\
\hline I & $0-7$ & 1 \\
\hline II & $8-26$ & 2 \\
\hline III & $27-52$ & 4 \\
\hline IV & $53-80$ & 6 \\
\hline
\end{tabular}

\section{RESULTADOS}

\section{Análise de microscopia}

As Figuras 2a e 2b apresentam, respectivamente, os resultados obtidos para a MEV em amostras coletadas antes da introdução do PCP e ao final da operação do reator.

Os resultados de todas as análises de microscopia indicaram a predominância de uma grande quantidade de bacilos não metanogênicos (não fluorescentes) em formatos variados. Apesar da presença em quantidade bem menor, também foram detectados

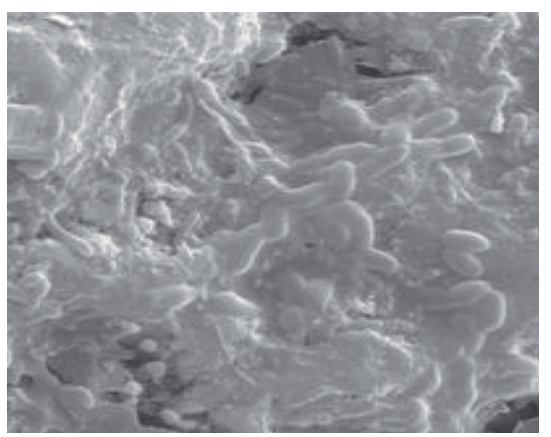

(a) outros tipos de células, semelhantes a cocos, bactérias filamentosas, bacilos metanogênicos, cistos de Methanosaeta $s p$ e Methanosarcina sp.

As análises realizadas apresentaram resultados muito similares no que diz respeito à variedade de microrganismos encontrados, mostrando que o PCP, nas concentrações utilizadas, aparentemente não proporcionou alterações qualitativas na biomassa. A população metanogênica também não foi afetada com o aumento da concentração de PCP ao longo do experimento, visto que células semelhantes a Methanosarcina sp foram encontradas tanto antes como depois da operação do reator com PCP.

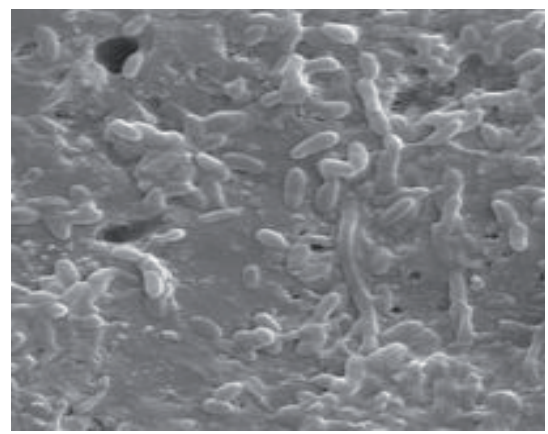

(b)
Figura 2 - Fotomicrografias (MEV) realizadas nas amostras de biopartículas antes da introdução do PCP (a) e após a operação do reator (b) 
Diante das evidências obtidas, é possível concluir que a composição qualitativa da biomassa foi determinada pelas características particulares do efluente utilizado (fonte única de carbono e quantidade reduzida de matéria orgânica), e que essa composição não sofreu alterações com a presença de PCP nas concentrações que foram empregadas.

\section{Desempenho do RALF}

Os dados obtidos para desempenho do reator em termos de concentração de DQO no afluente e no efluente, para as 4 fases operacionais, são apresentados na Figura 3. As variações nas concentrações de PCP afluente não alteraram o desempenho do reator com relação à remoção de DQO, característica que também pode ser verificada na Figura 4, que apresenta a eficiência de remoção de DQO $\left(\mathrm{E}_{\mathrm{DQO}}\right)$ para o período.

Nos 80 dias de operação, foi obtida uma DQO afluente média de 993,4 $\mathrm{mg} / \mathrm{L}$, bem próxima do valor previamente estipulado de $1000 \mathrm{mg} / \mathrm{L}$. A DQO efluente média para o mesmo período foi de $80,6 \mathrm{mg} / \mathrm{L}$.

A eficiência média de remoção de DQO para o período de operação com PCP foi de 91,9\%, sendo a eficiência mínima de $89,6 \%$ e a máxima de $95,0 \%$. Diante destes resultados, e observando o gráfico, é possível concluir que, nas concentrações de PCP utilizadas neste trabalho, não houve um processo de inibição da cinética de degradação de matéria orgânica por presença de substância tóxica. As eficiências de remoção de DQO foram similares, tanto para a fase com menor quanto maior concentração de PCP (fases I e IV, respectivamente). A Figura 5 mostra os resultados obtidos para a alcalinidade total (AT).

A alcalinidade total média no afluente, para os 80 dias de funcionamento com PCP, foi de 374,6 mg/L. $\mathrm{O}$ reator anaeróbio na presença do composto tóxico também produziu alcalinidade, como pode ser observado nas concentraçôes efluentes. A média foi de $682,3 \mathrm{mg} / \mathrm{L}$.

A geração de alcalinidade ao longo do processo anaeróbio, como se observa na Figura 5, é um bom indício de estabilidade. Os valores no efluente maiores que no afluente representam que a remoção de ácidos voláteis do sistema foi efetiva.

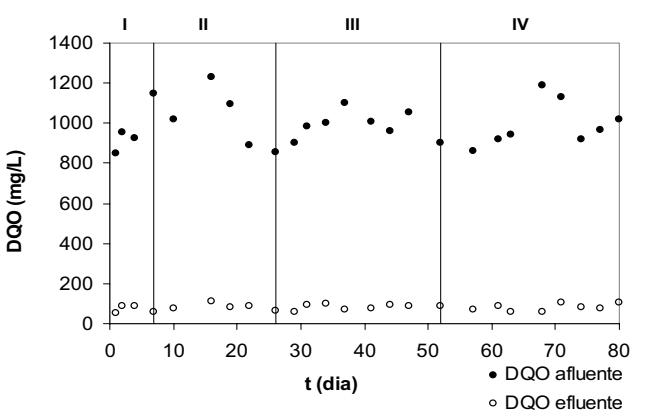

Figura 3 - Variação temporal da concentração de DQO no RALF

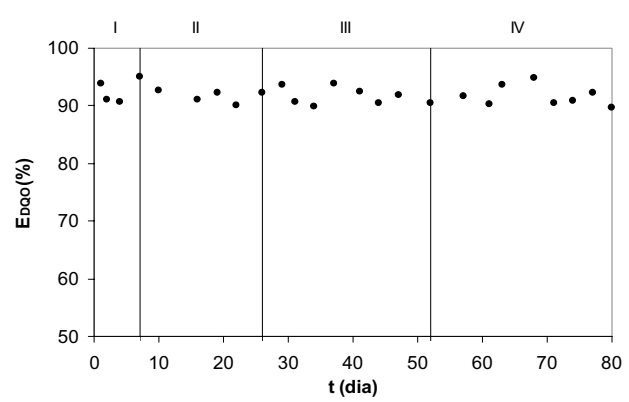

Figura 4 - Variação temporal da eficiência de remoção de DQO no RALF

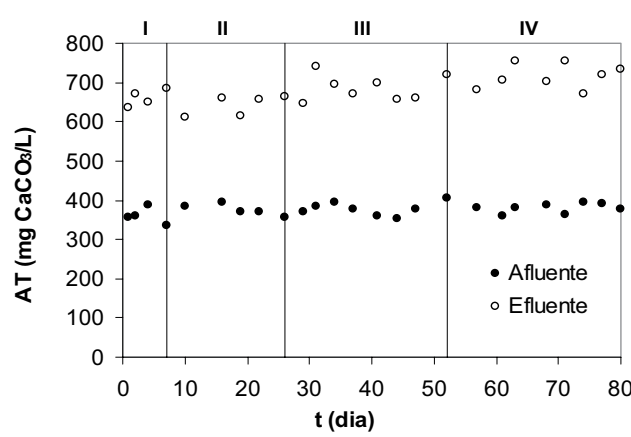

Figura 5 - Variação temporal da concentração de alcalinidade total (AT) do RALF

Em reatores biológicos, o acúmulo de ácidos orgânicos voláteis indica um desbalanceamento entre as velocidades de consumo de matéria orgânica, realizado pelos diferentes tipos de bactérias. A "harmonia" entre esse consumo de matéria orgânica, por sinal, é responsável pelo desempenho adequado do sistema de tratamento anaeróbio. Quando a concentração de ácidos voláteis se torna muito elevada, ou melhor, quando não existe mais efeito tampão devido à ausência de alcalinidade a bicarbonato, há probabilidade de ocorrência de problemas graves com o sistema de tratamento, devido à diminuição do $\mathrm{pH}$
(Speece, 1996). A geração de alcalinidade também é verificada analisando-se os valores de $\mathrm{pH}$. A Figura 6 mostra os valores obtidos no monitoramento do $\mathrm{pH}$ afluente e efluente

A média dos valores de $\mathrm{pH}$ medidos no afluente e no efluente foram de 6,53 e 8,16 , respectivamente. A introdução do PCP em pH elevado no afluente, devido à presença de $\mathrm{NaOH}$ na solução estoque, aparentou não ter interferido nos valores de alcalinidade e pH. Em comparação ao volume de efluente preparado diariamente, a pequena quantidade de solução estoque acrescentada foi insignificante para 
provocar qualquer modificação nestes parâmetros, tanto que em nenhum momento foi cogitada qualquer correção do $\mathrm{pH}$.

Nota-se que a alcalinidade total e o $\mathrm{pH}$ do efluente foram sempre superiores ao afluente, uma característica usual de reatores anaeróbios quando operam de maneira estável. Existem vários fatores que podem contribuir para que ocorram variaçōes na alcalinidade e no $\mathrm{pH}$, no dia-a-dia dos experimentos, pois é de conhecimento que os processos anaeróbios envolvem uma complexa seqüência de reações, com muitas variáveis envolvidas. Boa parte desses fatores está relacionada com as condiçôes operacionais aplicadas ao reator, dentre as quais as variações na vazão de alimentação, na vazão de recirculação, na composição da água residuária sintética, nas características das biopartículas, além dos próprios erros dos métodos de análise. Essas variações, mesmo que pequenas, poderão influenciar nos resultados e provocar maiores desvios nos parâmetros analisados.

A Figura 7 mostra os resultados obtidos para a concentração afluente de ácidos voláteis, já que o método de cromatografia não detectou ácidos voláteis no efluente do reator, para este período.

Todos os parâmetros de monitoramento do reator que foram descritos até este momento, ou seja, a remoção de matéria orgânica (em termos de DQO), a alcalinidade, o pH e a concentração de ácidos voláteis, demonstraram que o sistema se manteve estável nas condições operacionais aplicadas e que essa estabilidade não foi alterada com a presença de PCP nas concentrações estudadas.

Os dados obtidos para desempenho do reator, em termos de concentração de PCP no afluente e no efluente e eficiência de remoção de PCP $\left(\mathrm{E}_{\mathrm{PCP}}\right)$ são apresentados respectivamente nas Figuras 8 e 9.

$\mathrm{Na}$ fase I de funcionamento do reator, foi aplicada no afluente uma concentração média de $1,14 \mathrm{mg} / \mathrm{L}$ de PCP, obtendo-se uma concentração média no efluente de $0,09 \mathrm{mg} / \mathrm{L}$. A eficiência média da fase I foi de $92,3 \%$. $\mathrm{Na}$ fase II, a concentração média de PCP na entrada foi aumentada para $2,13 \mathrm{mg} / \mathrm{L}$, e no efluente foi verificada uma concentração média de PCP de $0,27 \mathrm{mg} / \mathrm{L}$, resultando em uma eficiência média de remoção de PCP de

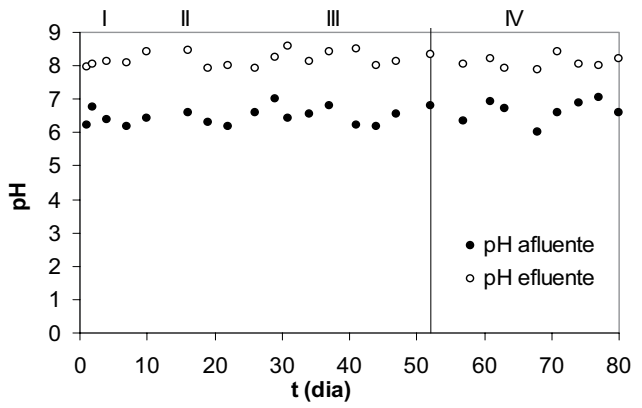

Figura 6 - Variação temporal dos valores de pH no RALF
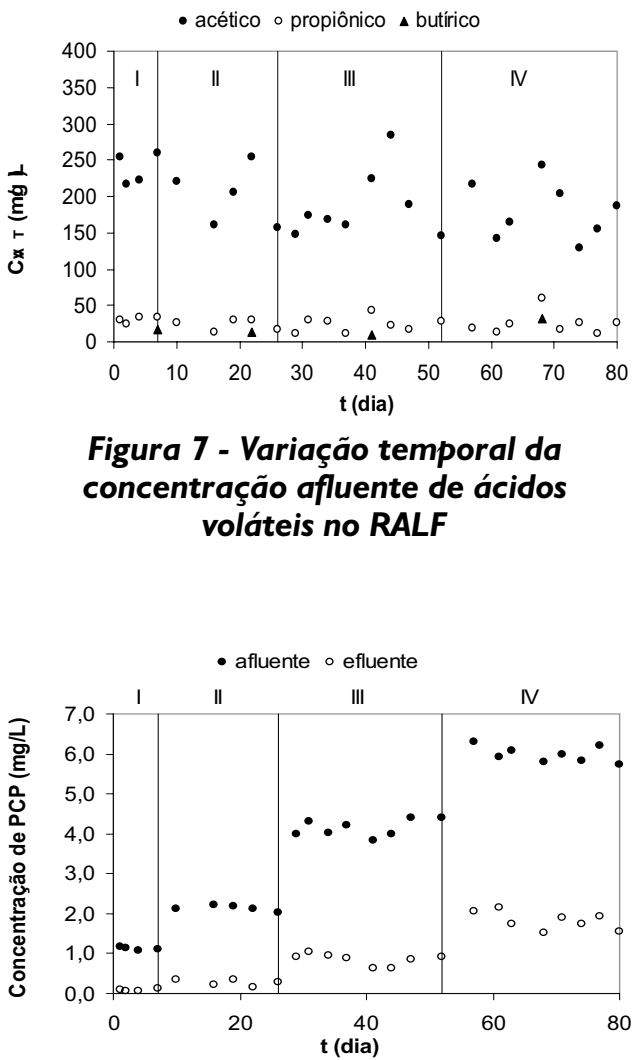

Figura 8 - Variação temporal da concentração de PCP no RALF

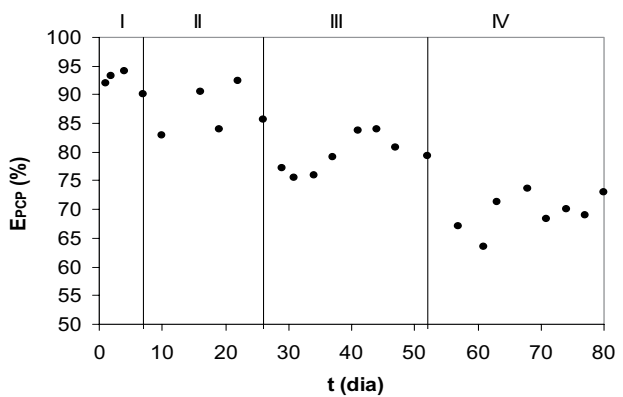

Figura 9 - Variação temporal da eficiência de remoção de PCP no RALF 
$87,1 \%$. Na fase III a concentração média de PCP afluente foi de $4,15 \mathrm{mg} / \mathrm{L}$, com uma concentração média efluente de $0,85 \mathrm{mg} / \mathrm{L}$. A eficiência média determinada para esta fase foi de $79,5 \%$. A última fase de funcionamento do reator teve como concentração média de PCP no afluente o valor de $5,98 \mathrm{mg} / \mathrm{L}$, e $1,83 \mathrm{mg} / \mathrm{L}$ no efluente. A eficiência de remoção média foi de $69,5 \%$.

As concentraçóes dos compostos intermediários detectados no efluente são apresentadas na Figura 10.

Apenas a partir do $30^{\circ}$ dia foram determinadas concentrações de triclorofenóis (TCP) no efluente do reator e os diclorofenóis (DCP) foram determinados a partir do $60^{\circ}$ dia. Sob este aspecto específico, Khodadoust et al (1997) obteve resultados semelhantes. No referido trabalho, apesar de ter sido introduzido no sistema a partir do $44^{\circ}$ dia de operação de um RALF, o PCP foi determinado no efluente apenas a partir do $100^{\circ}$ dia, e pequenas concentraçôes de TCP's e DCP's foram determinadas apenas por volta do $140^{\circ}$ dia de operação.

$\mathrm{O}$ aparecimento de compostos intermediários depois de um certo período de operação e o aumento da concentração destes compostos ao longo do tempo possivelmente estão relacionados com a própria adaptação do sistema. Damianovic (1997), que submeteu o lodo de inóculo a uma adaptação prévia ao PCP, determinou compostos intermediários desde o início da operação de um reator anaeróbio horizontal de leito fixo (RAHLF). Os intermediários TCP e DCP também foram encontrados no efluente. Além disso, as concentrações de tetraclorofenóis (TeCP) foram estimadas, partindo-se da hipótese de que $55 \%$ do PCP recuperado era convertido a TeCP's. Neste trabalho nenhum intermediário foi determinado através de estimativas.

Além de depender do nível de adaptação do sistema, a quantidade (e variedade) dos compostos intermediários também está relacionada com muitos fatores operacionais, dentre eles o tempo de detenção hidráulica aplicado. TDH mais elevados possibilitam uma melhor adaptação do sistema, em fases iniciais de operação, e também permitem que ocorram mais reaçōes de desalogenação. A presença de monoclorofenóis (MCP's) no efluente, por exemplo, implica que várias desalogenaçôes tenham ocorrido, a partir do

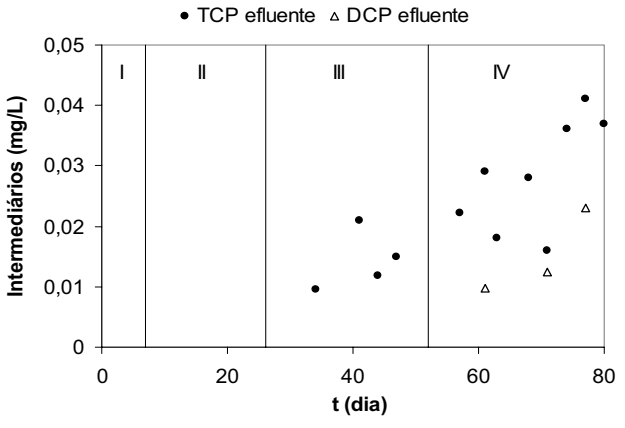

\section{Figura 10 - Variação temporal da concentração de clorofenóis intermediários no efluente}

PCP. Pelo mesmo raciocínio, a aplicação de TDH mais reduzidos possivelmente dificulta sucessivos processos de desalogenação.

\section{DISCUSSÃO}

Em suma, a eficiência média do reator na remoção de PCP para as concentrações utilizadas ficou entre $92 \%$ e $70 \%$. Os resultados indicam uma queda na eficiência de remoção de PCP principalmente quando foram aplicadas concentraçóes afluentes de $4 \mathrm{mg} / \mathrm{L}$ e $6 \mathrm{mg} / \mathrm{L}$. A análise do problema, entretanto, não deve se concentrar exclusivamente em termos da eficiência de remoção de PCP, pois este parâmetro está intimamente relacionado às condiçóes operacionais que foram aplicadas. Essa característica, inclusive, dificulta que sejam feitas comparaçōes aprofundadas com a literatura referente ao tema, pois cada trabalho atribui condições de funcionamento muito particulares.

Um aspecto comum, entretanto, encontrado nos trabalhos envolvendo reatores anaeróbios de leito fluidificado no tratamento de substâncias tóxicas foi o elevado tempo de operação, totalizando muitas vezes até mais de 1000 dias (Koran et al, 2001; Wilson et al, 1998). Essa condição mostra que, de todos fatores interferentes em um processo biológico de tratamento envolvendo reatores anaeróbios, parece ser a "especialização" da biomassa uma das características mais importantes. Em outras palavras, uma biomassa bem adaptada ao substrato de entrada (mesmo com um composto tóxico acrescido) possivelmente permitirá que sejam implementadas condiçôes mais similares às encontradas nas indústrias.
No caso dos reatores, essa adaptação pode ser alcançada através de longos tempos de operação, através do contato prévio, ou ainda de técnicas microbiológicas, como as de enriquecimento da biomassa.

Os reatores biológicos em escala industrial certamente irão operar em conjunto com outras unidades, muitas vezes fazendo o papel de pré-tratamento. Portanto, o reator anaeróbio de leito fluidificado estudado apresentou um desempenho satisfatório no cumprimento do seu objetivo principal, ou seja, o de ser uma unidade de prétratamento de um efluente contendo substância tóxica.

Foi possível ainda verificar que condições operacionais menos ideais podem ser aplicadas, tais como restrições no número de fontes de carbono e na quantidade de matéria orgânica, e ainda menores tempos de detenção hidráulica. Medidas simples como a introdução do PCP em incrementos menores, o aumento do TDH e do tempo de operação de cada fase poderiam até ter proporcionado resultados melhores, mas a proposta era justamente a de situar mais uma referência na linha temática de estudos relacionados com clorofenóis e reatores de leito fluidificado. Esse trabalho teve como princípio básico apresentar uma pequena contribuição ao processo de otimização dos reatores anaeróbios, principalmente os de leito fluidificado. Pelos próprios fundamentos da ciência e da tecnologia, a otimização será sempre um objetivo a ser alcançado.

\section{CONCLUSÕES}

A presença de PCP no sistema, nas concentraçôes utilizadas, não alterou a 
qualidade da biomassa presente, e nem os parâmetros de monitoramento de desempenho, como DQO, alcalinidade, pH e ácidos voláteis.

Mesmo sob condições menos idealizadas, foi observado um desempenho satisfatório do reator na remoção do composto tóxico pentaclorofenol. Em concentrações variando de 1 a $6 \mathrm{mg} / \mathrm{L}$, foram observadas eficiências médias de remoção de $92 \%$ e $70 \%$, respectivamente.

O reator anaeróbio de leito fluidificado em estudo cumpriu adequadamente a função de unidade de pré-tratamento de uma água residuária sintética contendo PCP.

$\mathrm{O}$ trabalho indicou que condiçôes operacionais mais simples podem ser utilizadas, oferecendo assim maiores subsídios para que em etapas posteriores, a modelagem, a simulação, a otimização e o controle desse tipo de reator sejam mais facilmente estudadas.

\section{AGRADECIMENTOS}

Os autores agradecem à Fapesp pelo financiamento da pesquisa.

\section{REFERÊNCIAS}

APHA. Standard methods for the examination for water and wastewater. American Public Healt Association. (APHA). 17 ${ }^{\text {th }}$ ed. New York, EUA, 1998.

ARAÚJO, J. C. et al. Methanogenic biofilm: structure and microbial population activity in an anaerobic fluidized bed reactor treating synthetic wastewater. Biofilm Journal, Inglaterra, v. 3, p. 1-14, 1998.

BASU, S.K. et al. Dehalogenation of 2-chlorophenol (2CP) in anaerobic batch culture. Water Research, v. 30, n. 02 , p. $315-322,1996$.

BLAKLEY, B. R. et al. Effect of pentachlorophenol on immune function. Toxicology, v.125, n. (2-3), p.141-148, 1998.

BRIENS, L.A. et al. Minimum liquid fluidization velocity in Gás-Liquid-Solid fluidized beds. AIChE Journal, v. 43, p. 1180-1189, 1997.

BUZZINI, A.P.; PIRES, E.C. Cellulose pulp mill effluent treatment in an anaerobic sludge blanket reactor. Process Biochemistry, v. 38, p. 707-713, 2002.

CAMPOS, J.R.; PEREIRA, J.A.R. Reator anaeróbio de leito expandido/fluidificado. In: CAMPOS, J.R. (Ed.). Tratamento de esgotos sanitários por processo anaeróbio e disposição controlada no solo. Rio de Janeiro: PROSAB, cap. 8, p. $199-219$, 1999.

CHEN, C.Y.; CHEN, S.D. Biofilm characteristics in biological denitrification biofilm reactors. Water Science and Technology, v.41, n.4, p 147-154, 2000 .
DAMIANOVIC, M.H.R.Z. Degradação de pentaclorofenol (PCP) em reatores anaeróbios horizontais de leito fixo (RAHLF). Tese (Doutorado) - Escola de Engenharia de São Carlos, Universidade de São Paulo, São Carlos, 175p., 1997.

DAMIANOVIC, M.H.R.Z. et al. Gas chromatographic methods for monitoring of wastewater chlorophenol degradation in anaerobic reactors. Journal of Environmental Science and Health. Part B, Pesticides, Food Contaminants, and Agricultural Wastes, v. 42, p. 45-52, 2007.

FIELD, J.A. et al. Enhanced biodegradation of aromatic pollutants in cocultures of anaerobic and aerobic bacterial consortia. Antonie Van Leeuwenhock, v. 77, p. $47-77,1995$.

FLORA, J.R.V. et al. Anaerobic treatment of a simulated high-strength industrial wastewater containing chlorophenols. Water Enviromental Research, v. 66, n.1, p.21-31, 1994.

GARDNER, D.A. et al. Role of GAC activity and particle size during the fluidized-bed anaerobic treatment of refinery sour water stripper bottoms. J. Wat. Pollut. Control Fed., v. 60, p.505-513, 1988.

KHODADOUST, A.P. et al. Anaerobic treatment of PCP in fluidized-bed GAC bioreactors. Water Research, v. 31, p.1776-1786, 1997.

KORAN, K.M. et al. Effectiveness of an anaerobic granular activated carbon fluidized-bed bioreactor to treat soil wash fluids: a proposed strategy for remediating PCP/PAH contaminated soils. Water Research, v. 35, n.10, p.2363-2370, 2001.

METCALF e EDDY. Wastewater Engineering -Treatment-Disposal-Reuse. Thirth Edition. New York: McGraw-Hill International Editions, 1991.

MIURA, H.; KAWASE, Y. Minimum liquid fluidization velocity in two-phase fluidized beds with non-Newtonian fluids. Powder Technology, v. 97, p.124-128, 1998.

MORAES, E. M. et al. Determinação de ácidos voláteis por cromatografia gasosa em efluentes de reatores anaeróbios. In: Pós-tratamento de efluentes de reatores anaeróbios - aspectos metodológicos. Belo Horizonte: Editora Belo Horizonte: FINEP - PROSAB, v. , p. 35-42. 2001.

NERY, V.; DAMIANOVIC, M. H. R. Z.; BARROS, F. G. The use of upflow anaerobic sludge blanket reactor in the treatment of poultry slaughterhouse. Water Science and Technology, v. 44, p. 83-88, 2001.

PARKER, W.J. et al. Evaluation of dechlorination mechanisms during anaerobic fermentation of bleached Kraft Mill effluent. Water Research, v. 27, n. 08 , p. $1269-1273,1993$.

PFEFFER, J.T.; SUIDAN, M.T. Continuous processing of toxic organics in a fluidized-bed GAC reactor employing carbon replacement. Biotech. Bioeng., v. 33, p.139-148, 1989.

SAFONIUK, M. et al. Use of dimensional similitude for scale-up of hydrodynamics in three-phase fluidized beds. Chemical Engineering Science, v. 54, p.4961-4966, 1999.

SAIA, F.T. Contribuição à exploração tecnológica dos estudos microbianos realizados no programa BIOTA FAPESP: avaliação do potencial da degradação anaeróbia de pentaclorofenol (PCP) em reator anaeróbio horizontal de leito fixo (RAHLF). Tese (Doutorado) - Escola de Engenharia de São
Carlos, Universidade de São Paulo, São Carlos, 206p., 2005.

SILVA, A. J. et al. Evaluation of support materials for the immobilization of sulfate-reducing bacteria and methanogenic archaea. Anaerobe, v. 12, p. 93-98, 2006.

SPEECE, R. Anaerobic Biotechnology for Industrial Wastewaters. Tennessee: Archae Press, 1996.

SUIDAN, M.T. et al. Anaerobic dechlorination using a fluidized-bed GAC reactor. Water Research, v.30, p.160-170, 1996.

TSUNO, H. et al. Anaerobic degradation of pentachlorophenol (PCP) in biological expanded-bed reactor. Wat. Sci. Tech.trol Fed. v.34, p.335-344, 1996.

WANG, Y. et al. Anaerobic treatment of phenol by an expanded bed reactor. J. Wat. Pollut. Control Fed., v.58, p.227-233, 1986

WILSON, G.J. et al. Anaerobic/Aerobic biodegradation of pentachlorophenol using GAC fluidized-bed reactors: optimization of the empty bed contact time. Wat. Sci. Tech., v.38, n.7, p.9-17, 1998

\section{Endereço para correspondência:}

Flavio Bentes Freire

Centro de Tecnologia

Universidade Estadual de

Maringá

Rodovia PR 489, 1400

87508-2 10 Umuarama - PR -

Brasil

Tel.: (44) 362 I-9300

E-mail: fla_freire@yahoo.com.br 